\title{
Clinical Findings and Predictors of Mortality in 354 COVID-19 Cases; a Report from a Tertiary Center in Tehran, Iran.
}

\author{
Helia Mojtabavi ${ }^{1}$, Majid Sorouri ${ }^{1}$, Amir Kasaeian ${ }^{1}$, Bahar Saberzadeh-Ardestani ${ }^{1}$, Amir \\ Reza Radmard ${ }^{1}$, Bardia Khosravi ${ }^{1}$, Masoud Eslahi ${ }^{1}$, Azin Sirusbakht ${ }^{1}$, Seyed Mohammad \\ Pourabbas $^{1}$, Marjan Khodabakhshi ${ }^{1}$, Fatemeh Motamedi ${ }^{1}$, Fatemeh Azizi ${ }^{1}$, Zeynab \\ Rajabi $^{1}$, Leila Aghaghazvini ${ }^{1}$, Sara Naybandi Atashi ${ }^{1}$, Shahin Merat ${ }^{1}$, Ahmadreza \\ Jamshidi $^{1}$, Reza Malrkzadeh ${ }^{1}$, Alireza Sima ${ }^{1}$, and Mohammad Abdollahi ${ }^{1}$ \\ ${ }^{1}$ Tehran University of Medical Sciences
}

May 19, 2020

\begin{abstract}
OBJECTIVE We reported the clinical characteristics, laboratory findings, and radiologic features of a COVID-19 registry in Iran and compared disease manifestations between the deceased patients and those who recovered. DESIGN This was a retrospective cross-sectional study with census sampling. SETTING Three hundred forty-five patients were enrolled from February 25th, 2020, to April 21st, 2020, in a tertiary referral hospital. PARTICIPANTS Patients with suggestive lung computed tomography scans (CT scans) who had respiratory symptoms and one of the followings: 1) loss of consciousness, 2) Respiratory rate more than 24,3) pulse rate more than 90,4) Systolic blood pressure less than $90 \mathrm{mmHg}, 5$ ) abnormal respiratory sounds, or 6) O2 saturation less than $93 \%$ or high-risk patients with respiratory symptoms or fever were enrolled to the study. MAIN OUTCOME MEASURES The primary outcome measures were days of hospital stay, any event of intubation, ICU admission, and in-hospital death. Logistic regression was done to assess the association between survival status and patients' characteristics. RESULTS Nearly $45 \%$ of patients were older than 65 years, and $57.6 \%$ were male. Twenty hundred and sixty-five patients $(74.8 \%)$ survived. Univariate analysis showed a significant association between mortality and older age, higher body mass index, aspartate transaminase, consciousness, cancer, organ transplant, oxygen saturation (SO2), systolic and diastolic blood pressure, body temperature, respiratory rate, pulse rate, anemia, leukocytosis, neutrophil to lymphocyte ratio (NLR), thrombocytopenia, creatinine, CRP, PH, PCO2, and bicarbonate. The relationship between mortality and consciousness, cancer, low SO2, tachycardia, platelet count less than 150,000 per microliter of blood, creatinine over $1.2 \mathrm{mg} / \mathrm{dL}$ remained statistically significant in multivariate analysis. The average total length of hospital stay was 5.98 days (SD: 5.87). CONCLUSION We observed that increased tachycardia, high-grade fever, tachypnea, and NLR strongly correlated with in-hospital death. In contrast, higher levels of systolic blood pressure had a protective role.
\end{abstract}

Keywords: COVID-19, SARS-CoV-2, Coronavirus, Clinical characteristics, Mortality, Intubation

\section{Introduction}

Starting in late December 2019, several patients with acute respiratory illnesses raised in China. On January $7^{\text {th }}$, the Chinese Center for Disease Control and Prevention (CDC) declared that a novel coronavirus, SARS-COV $-2^{*}$, was detected from the throat swab sample of one of their patients. Presenting mainly with respiratory symptoms, the disease was subsequently called Coronavirus disease (COVID-19) by the World Health Organization (WHO) (Adalja, Toner, \& Inglesby, 2020; N. Chen et al., 2020; Diao et al., 2020). The rapid emergence of COVID-19 led WHO authorities to announce pandemic on late march 2020 ("WHO 
Pandemic declaration (April 17th 2020) https://www.who.int/dg/speeches/detail/who-director-general-sopening-remarks-at-the-media-briefing-on-covid-19-11-march-2020 "). By May $5^{\text {th }}$, confirmed cases outreached 3,747,292 from 212 countries with overall 258,962 death ("Worldometers (April 29th 2020) Number of affected COVID-19 worldwide https://www.worldometers.info/coronavirus/\#countries,"). Infections with novel coronavirus manifest as fever, nonproductive cough, dyspnea, myalgia, fatigue, anorexia, anosmia, lymphopenia, and evidence of pneumonia on radiographic studies. Symptoms' severity could range from mild self-limiting symptoms to severe pneumonia, acute respiratory distress syndrome (ARDS), or multiple organ failure (X. Chen et al., 2020).

Although Iran is among the top countries with exceeding the number of COVID-19 cases since March 2020, few reports are available on the clinical picture, management, and ultimate disease course of our patients. By this case series, we aim to describe the epidemiologic features alongside the clinical presentations, and outcomes from 354 patients with confirmed COVID-19 in Iran.

* severe acute respiratory syndrome coronavirus 2

\section{Materials and Method}

\section{Study Design and participants}

In a retrospective cross-sectional study at Shariati hospital in Tehran, Iran, we included all patients admitted with the diagnosis of COVID-19 based on the criteria published by WHO on January 12th, 2020 (WHO.), from February 25th, 2020, to April 21st, 2020. Patients with respiratory symptoms and one of the followings were admitted to the hospital: 1) loss of consciousness, 2) Respiratory rate more than 24, 3) pulse rate more than 90,4) Systolic blood pressure less than $90 \mathrm{mmHg}, 5)$ abnormal respiratory sounds, or 6) O2 saturation less than $93 \%$. Furthermore, high-risk patients with respiratory symptoms or fever underwent computed tomography scans of the lung (CT scans). In case of a suggestive lung CT scan of COVID-19 infection, the patients were transferred to the COVID ward. Patients with a negative lung CT scan underwent further workup. Patients who were already admitted to the hospital were transferred to the COVID ward if they experienced COVID-19 infection during hospitalization. We used the census sampling method, and after exclusion of cases with missed data, four hundred and four patients were selected. Two radiologists reviewed all the images and patients with not suggestive lung CT scan and negative SARS-CoV2 RT-PCR were excluded. We extracted clinical data, laboratory findings, and lung CT scans from the remaining three hundred fifty-four patients' medical records. The study was approved by the ethics committee of Tehran University of Medical Sciences. The ethics committee waived the requirement for informed patient consent for this retrospective study subject to the anonymity of patients.

\section{Measurements}

The variables recorded are given in Table A.

Table A: variables recorded and their categorization.

History and physical examination:

Age: young adults (<50 years old), middle-age ( $50-65$ years old), and elderly ( $>65$ years old) Sex: Male, Female Body mass Past Medical History:

Diabetes (DM), hypertension (HTN), ischemic heart disease (IHD), Chronic kidney disease (CKD), cancer, organ transplan Laboratory Findings:

complete blood cell count (CBC), Ratio of circulating neutrophil to lymphocyte count (NLR) C-reactive protein (CRP), Cr Lung CT Scan:

ground-glass opacity consolidation bilateral involvement 
The q-SOFA score was calculated for all patients, and a patient with qSOFA Score [?]2 was categorized as high risk (Seymour et al., 2016).

Outcomes included days of hospital stay, any event of intubation, ICU admission, and in-hospital death.

\section{Statistical analysis}

Categorical variables were described in frequencies and percentages. Quantitative variables were described with the mean (Standard deviation (SD)) or median and [Q1 - Q3]. Parametric and nonparametric tests, including t-test and Mann-Whitney test for comparing quantitative variables and Chi-squared test for comparing categorical variables were used. In a first step, variables showing associations at a significance level of $\alpha=0.20$ in a univariable logistic models were selected for inclusion in the multivariable logistic model for adjustment. Statistical analyses were performed using Stata (Corp. 2009. Stata Statistical Software: Release 11. College Station, TX: StataCorp LP.). Statistical significance was defined as $\mathrm{P}<0.05$.

\section{Results}

Data about surviving and not surviving patients' characteristics, signs and symptoms, PMH, physical examination, and outcomes are presented in Table 1. Nearly $45 \%$ of patients were older than 65 years, $57.6 \%$ were male. $16.6 \%$ of dead patients were severely obese, with a significant difference between alive and dead patients $(\mathrm{P}$-value $<0.012)$. Weakness was the most common sign. The most prevalent comorbidities were HTN and DM (35.88\% and 30.52\%, respectively), and only $21 \%$ of patients did not have any comorbidities. Since Shariati hospital is a tertiary referral center, a remarkable portion of the patients (approximately $20 \%$ ) had degrees of immune deficiencies. Positive COVID-19 RT-PCR was detected in $53.07 \%$ of our study population.

The not high-risk group (q-SOFA score: one) was associated with almost four times greater odds of death (CI: 2.42-7.3, P-value<0.001), and the high-risk group (q-SOFA score: two) was associated with over ten times odds of death (CI: 2.98-36.04, P-value $<0.001)$. Four of the patients had a q-SOFA score of three, whom all died during hospitalization. Systolic and diastolic blood pressure were both significantly different between alive and dead patients ( $\mathrm{P}=0.001$, and 0.024 , respectively).

The average length of hospital stay was 5.98 days (SD:5.87). Twenty hundred and sixty-five patients (74.8\%) recovered. The average hospital stay for recovered patients was 5.07 days (SD: 4.58), and the mean number of days until death was 8.6 (SD:8.03). Of 354 patients, 64 patients (18.08\%) did not require any oxygenation support. 117 patients were admitted to ICU of which $82 \%$ were intubated during hospitalization and $72 \%$ died. Twenty-eight patients $(7.91 \%)$ received noninvasive ventilation support.

Data about surviving and not surviving patients' laboratory results and lung CT scans are shown in Table 2. The most prevalent lung CT scan finding was bilateral involvement and ground-glass opacities, with no significant differences between surviving and not surviving patients. Conversely, consolidation was significantly more common among non-surviving patients. CT scan characteristics were not entered into multivariate analysis since the p-value was borderline. Leukocytosis was significantly more common among not surviving patients $(\mathrm{p}<0.018)$. Also, NLR with a median of 4.23 (IQR; 2.8-7.45) among surviving patients was significantly lower than non-surviving patients with a median of 7.95 (IQR; 3.65-14.8) (p<0.001). Although AST was significantly different between alive and dead patients $(\mathrm{p}=0.002)$, indicators of liver function such as PTT and INR were not significantly different between the groups.

Univariate and multivariate analysis of the association between age, sex, anorexia, cancer, organ transplant, consciousness, vital signs, and laboratory results and survival are given in Table 3 .

Among patient's characteristics, old age, impaired consciousness, cancer, organ transplant, and BMI $>35$ were significantly associated with higher mortality. Details are given in table 3. Impaired consciousness 
increased odds of death around thirteen times (95\%CI: 5.62-32.97, $\mathrm{p}<0.001)$, and organ transplant was associated with almost eleven times higher risk of death (95\% CI: 2.29-55.10, $\mathrm{p}=0.003)$. The odds of death was 3.02 times higher in BMI above 35, and it reached 7.6 in the case of BMI exceeding 40 ( $\mathrm{p}=0.016$ and 0.0005 , respectively).

Low $\mathrm{SO}_{2}$, high-grade fever, tachypnea, and tachycardia were correlated with a higher death rate. Details are shown in table 3. Additionally, not surviving patients had a higher frequency of SBP below $100 \mathrm{mmHg}$ (OR: 2.68, 95\%CI:1.18-6.09, $\mathrm{p}=0.019)$, and SBP above $140 \mathrm{mmHg}$ was associated with 0.45 times lower odds of death (95\% CI:0.23-0.86, $\mathrm{p}=0.016)$.

Among laboratory findings, anemia, leukocytosis, platelet count less than 150,000 per microliter of blood, higher creatinine, and $\mathrm{pH}<7.25$ were significantly more frequent in non-surviving patients. Details are presented in table 3. Finally, we chose the median of CRP as the cutoff, and high CRP was correlated with greater mortality (OR: 2.29, 95\%CI: 1.9-5.69, p<0.001).

Given a large number of missing data, we did not enter BMI, and AST into multivariate analysis. Also, we did not enter NLR, SBP, PCO2, and bicarbonate into the multivariate analysis due to the correlation with WBC count, DBP, and PH, respectively. The univariate analysis of the variables which we did not enter into multivariate analysis because of the reasons mentioned above is presented in the supplemental table.

The relationship between low consciousness, cancer, low $\mathrm{SO}_{2}$, tachycardia, platelet $<150,000$ per microliter of blood, creatinine $>1.2 \mathrm{mg} / \mathrm{dL}$ remained statistically significant after multivariate analysis.

\section{Discussion}

In this case series, we report the clinical characteristics and risk factors associated with outcomes in COVID19 patients admitted to Shariati hospital, Tehran, Iran. Our study comprehensively describes clinical presentations and laboratory findings alongside with radiologic features of a COVID-19 registry among the Iranian population. The study investigates whether patients who died of COVID-19 are different from those who recovered in the disease course.

Sex showed no correlation with the mortality rate in our study population. Deceased cases were significantly older compared to the surviving patients, which is in line with previous studies (T. Chen et al., 2020; Zhou et al., 2020). Although the difference in body mass index (BMI) was not statistically significant within the study subgroups $(\mathrm{p}=0.3436)$, Severe and morbidly obese patients were at higher risk of death. This was similar to a study by Simonnet et al. that showed a correlation between BMI above 35 and the severity of the disease, and also in-hospital death (Simonnet et al., 2020). Unfortunately, due to the unavailability of $\mathrm{BMI}$ in every patient, we were unable to analyze it further.

Within the presenting symptoms, impaired consciousness, ranging from mild disorientation to stupor, significantly increased mortality. Impaired consciousness showed a strong impact on the patients' final outcome, affecting the moribund group 13 times more than the survived ones. In regards to neurologic manifestations, Mao et al. also observed 14.8\% of their severe cases had impaired levels of consciousness (Mao et al., 2020).

Analyzing baseline vital signs values on admission led to impressive conclusions. Body temperature over $39{ }^{\circ} \mathrm{C}$ was strongly suggestive of mortality in our sample. We noticed systolic blood pressure (SBP) higher than $140 \mathrm{mmHg}$ on admission lowers the mortality rate down to $60 \%$ while SBP below $100 \mathrm{mmHg}$ increased the risk of mortality up to around three folds, which is inconsistent with prior observation indicating the association of higher levels SBP with severe clinical picture (Huang et al., 2020).

Besides, RR more than 25 and PR values over 100 were significantly associated with a higher mortality rate. Among them, PR remained statistically significant in our ultimate logistic regression model with multiple variants as well. This strong ability of a single component in physical examination to predict disease course is quite remarkable. There is a lack of correlation between PR patterns with other suggestive, inflammatory 
variables such as CRP and temperature in our multivariate analysis. Thus, we hypothesize that besides systemic inflammation responses, higher PR could arise from additional cardiac involvement by the virus independent of mere inflammation. Similarly, in a study by Zhou et. Al. PR [?]125 and RR >24 were associated with a higher risk of mortality, although none of the two variables remained in the multivariate analysis to assess their correlation to others (Zhou et al., 2020).

Analyzing the CT scan findings of the patients' lung involvement revealed consolidative opacities as the significant imagining manifestation within our population. Bernheim et al. also suggest bilateral and peripheral ground-glass and consolidative pulmonary opacities as the hallmarks of COVID-19 infection on imaging (Bernheim et al., 2020).

History of HTN prior to hospital admission did not significantly increase the risk of mortality in our study population. This observation is inconsistent with prior studies reporting the adverse role of HTN in the COVID-19 course. HTN is repeatedly reported as the most prevalent comorbidity among COVID-19 patients (Huang et al., 2020; Wu et al., 2020). Moreover, a recent meta-analysis by Lippi et al. concluded that HTN is associated with a 2.5-fold higher risk of severe disease course or mortality in SARS-Cov-2 infections (Lippi, Wong, \& Henry, 2020). Probably our small number of subjects has not allowed us to detect this association as evident by our wide $95 \%$ CI. In addition, it is not clear whether poor BP control had contributed to severe symptoms and morbidity among the hypertensive population, or the mortality was due to the higher frequency of HTN in the older population, which are more vulnerable to COVID-19 infection (Schiffrin, Flack, Ito, Muntner, \& Webb, 2020).

We observed that venous blood acidosis was associated with increased mortality. Severe acidosis ( $\mathrm{pH}$ of 7.25 or lower) led to 4 times higher mortality, and $\mathrm{PCO}_{2}$ below $35 \mathrm{mmHg}$ was associated with a 2.5 -fold increase in mortality. Since no statistically significant correlation was detected between $\mathrm{PCO}_{2}$ and RR, their attribution to mortality is independent. In addition, blood bicarbonate contents below $22 \mathrm{mmol} / \mathrm{L}$ led to 2.6 times more mortality than higher levels.

Along with the existing claim on the higher incidence of in-hospital death by an increase in neutrophil to lymphocyte ratio (NLR), our data also revealed higher NLR in the deceased group compared to the recovered patients. Liu et al. concluded NLR as an independent risk factor of the in-hospital mortality, especially within their male candidates (Liu et al., 2020). Besides, Qin et al. noticed a statistically significant higher number of neutrophils alongside with a lower number of lymphocytes in severe to critical patients compared to non-severe cases. This describes the positive association of Neutrophilia or lymphopenia with disease severity and increased rate of death (Qin et al., 2020). Ultimately a recent meta-analysis by Lagunas-Rangel confirms the strong association between higher levels of NLR to death in COVID-19 patients (LagunasRangel).

Since only 166 cases in our study population had their urine analyzed the consequent data is not strongly representative. However, serum creatinine levels alongside proteinuria were significantly detected higher in the deceased subgroup compared to the recovered patients. Based on a recent study by Xu et al., ACE2 expresses equally in kidney cells in comparison to that in the lung, esophagus, small intestine, and colon. This suggests that the kidney could be considered as an important target organ for SARS-CoV-2, but further studies should address this issue $(\mathrm{Xu})$.

It is noteworthy that our study was conducted in a tertiary referral center which is among the most wellknown and well-equipped centers in Tehran, especially in internal medicine subspecialties. Keeping this in mind, during the recent outbreak, the number of patients with long-term rheumatologic complaints was diagnosed with confirmed SARS-COV-2 infection far less than patient with other chronic diseases such as cancers in our center (11 and 40 respectively). Hence, we hypothesize that consuming anti-inflammatory drugs would protect the patients from the new coronavirus infection due to confirmed inflammatory responses caused by COVID-19. 


\section{CONCLUSION}

In conclusion, we observed that increased PR, RR, body temperature and NLR strongly correlates with mortality. Contrary to prior findings, higher levels of systolic blood pressure (SBP) upon admission played a protective role in our patients. Our results also suggest that multiple organs are damaged in COVID-19 patients and direct virus-induced cytopathic effects might be involved rather than a mere systemic inflammatory response.

\section{Limitations of the study}

Our sample size of 354 patients could not be a proper representative of the general COVID-19 patients in Iran. Moreover, our cross-sectional study design fails to prove causality due to the temporality of variables association.

\section{Acknowledgement}

We cordially appreciate the effort of beyond 120 staff physicians, residents and interns in the current outbreak management in the Shariati hospital, Tehran, Iran.

\section{Declaration of interests}

We declare no competing interests.

\section{Data Availability statement}

The data that support the findings of this study are available on request from the corresponding author. The data are not publicly available due to privacy or ethical restrictions

\section{References}

Adalja, A. A., Toner, E., \& Inglesby, T. V. (2020). Priorities for the US Health Community Responding to COVID-19. Jama . doi:10.1001/jama.2020.3413

Bernheim, A., Mei, X., Huang, M., Yang, Y., Fayad, Z. A., Zhang, N., . . . Chung, M. (2020). Chest CT Findings in Coronavirus Disease-19 (COVID-19): Relationship to Duration of Infection. Radiology, 200463. doi:10.1148/radiol.2020200463

Chen, N., Zhou, M., Dong, X., Qu, J., Gong, F., Han, Y., . . . Zhang, L. (2020). Epidemiological and clinical characteristics of 99 cases of 2019 novel coronavirus pneumonia in Wuhan, China: a descriptive study.Lancet, 395 (10223), 507-513. doi:10.1016/s0140-6736(20)30211-7

Chen, T., Wu, D., Chen, H., Yan, W., Yang, D., Chen, G., . . . Wang, H. J. B. (2020). Clinical characteristics of 113 deceased patients with coronavirus disease 2019: retrospective study. 368 .

Chen, X., Zhao, B., Qu, Y., Chen, Y., Xiong, J., Feng, Y., . . . Li, F. (2020). Detectable serum SARS-CoV-2 viral load (RNAaemia) is closely associated with drastically elevated interleukin 6 (IL-6) level in critically ill COVID-19 patients. 2020.2002.2029.20029520. doi:10.1101/2020.02.29.20029520\%J medRxiv 
Diao, B., Wang, C., Tan, Y., Chen, X., Liu, Y., Ning, L., . . . Chen, Y. (2020). Reduction and Functional Exhaustion of T Cells in Patients with Coronavirus Disease 2019 (COVID-19). 2020.2002.2018.20024364. doi:10.1101/2020.02.18.20024364 \%J medRxiv

Huang, C., Wang, Y., Li, X., Ren, L., Zhao, J., Hu, Y., . . . Cao, B. (2020). Clinical features of patients infected with 2019 novel coronavirus in Wuhan, China. Lancet, 395 (10223), 497-506. doi:10.1016/s01406736(20)30183-5

Lagunas-Rangel, F. A. Neutrophil-to-lymphocyte ratio and lymphocyte-to-C-reactive protein ratio in patients with severe coronavirus disease 2019 (COVID-19): A meta-analysis. n/a (n/a). doi:10.1002/jmv.25819

Lippi, G., Wong, J., \& Henry, B. M. J. P. a. o. i. m. (2020). Hypertension and its severity or mortality in Coronavirus Disease 2019 (COVID-19): a pooled analysis.

Liu, Y., Du, X., Chen, J., Jin, Y., Peng, L., Wang, H. H., . . . Zhao, Y. J. J. o. I. (2020). Neutrophil-tolymphocyte ratio as an independent risk factor for mortality in hospitalized patients with COVID-19.

Mao, L., Wang, M., Chen, S., He, Q., Chang, J., Hong, C., . . . Hu, Y. (2020). Neurological manifestations of hospitalized patients with COVID-19 in Wuhan, China: a retrospective case series study.

Qin, C., Zhou, L., Hu, Z., Zhang, S., Yang, S., Tao, Y., . . . Tian, D.-S. (2020). Dysregulation of Immune Response in Patients With Coronavirus 2019 (COVID-19) in Wuhan, China. Clinical Infectious Diseases . doi:10.1093/cid/ciaa248

Schiffrin, E. L., Flack, J. M., Ito, S., Muntner, P., \& Webb, R. C. J. A. J. o. H. (2020). Hypertension and COVID-19.

Seymour, C. W., Liu, V. X., Iwashyna, T. J., Brunkhorst, F. M., Rea, T. D., Scherag, A., . . . Angus, D. C. (2016). Assessment of Clinical Criteria for Sepsis: For the Third International Consensus Definitions for Sepsis and Septic Shock (Sepsis-3). JAMA, 315 (8), 762-774. doi:10.1001/jama.2016.0288

Simonnet, A., Chetboun, M., Poissy, J., Raverdy, V., Noulette, J., Duhamel, A., . . . Jourdain, M. J. O. (2020). High prevalence of obesity in severe acute respiratory syndrome coronavirus-2 (SARS-CoV-2) requiring invasive mechanical ventilation.

WHO Pandemic declaration (April 17th 2020) https://www.who.int/dg/speeches/detail/who-directorgeneral-s-opening-remarks-at-the-media-briefing-on-covid-19-11-march-2020

WHO. WHO (January 28th 2020) Clinical management of severe acute respiratory infection when novel coronavirus $(2019 \mathrm{nCoV})$ infection is suspected: interim guidance. January 28, 2020. https://www.who.int/docs/defaultsource/coronaviruse/clinicalmanagementofnovelcov.pdf

Worldometers (April 29th 2020) Number of affected COVID-19 worldwide https://www.worldometers.info/coronavirus/\#countries.

Wu, C., Chen, X., Cai, Y., Zhou, X., Xu, S., Huang, H., . . . Zhang, Y. J. J. i. m. (2020). Risk factors associated with acute respiratory distress syndrome and death in patients with coronavirus disease 2019 pneumonia in Wuhan, China.

Xu, D. Z., H.; Gong, H.; Chen, J.; Ye, J.; Meng, T.; Gan, S.; Qu, F.; Chu, C.; Zhou, W.; Pan, X.; Wang, L.; Cui, X. . Identification of a Potential Mechanism of Acute Kidney Injury During the Covid-19 Outbreak: A Study Based on Single-Cell Transcriptome Analysis. . Preprints 2020, 2020020331 .

Zhou, F., Yu, T., Du, R., Fan, G., Liu, Y., Liu, Z., . . . Gu, X. J. T. L. (2020). Clinical course and risk factors for mortality of adult inpatients with COVID-19 in Wuhan, China: a retrospective cohort study.

Table 1. Demographics, baseline characteristics, and outcome of our 354 patients. 


\begin{tabular}{|c|c|c|c|c|}
\hline & Total n $\left(\%^{\#}\right)$ & Survived n (\%) & Non-Survived n (\%) & $\mathrm{p}$-value \\
\hline & Total n $(\% \#)$ & Survived n (\%) & Non-Survived n (\%) & p-value \\
\hline \multicolumn{5}{|l|}{$\overline{\text { Age }}$} \\
\hline$<5050-65>65$ & $\begin{array}{l}77(21.75) 118 \\
(33.33) 159(44.92)\end{array}$ & $\begin{array}{l}66(24.91) 94 \\
(35.47) 105(39.62)\end{array}$ & $\begin{array}{l}11(12.36) 24 \\
(26.97) 54(60.67)\end{array}$ & 0.002 \\
\hline \multicolumn{5}{|l|}{ Sex } \\
\hline Female Male & $\begin{array}{l}150(42.37) 204 \\
(57.63)\end{array}$ & $\begin{array}{l}119(44.91) 146 \\
(55.09)\end{array}$ & $\begin{array}{l}31(34.83) 58 \\
(65.17)\end{array}$ & 0.096 \\
\hline \multicolumn{5}{|l|}{ BMI } \\
\hline$<35>35$ & $\begin{array}{l}220(91.67) 20 \\
(8.33)\end{array}$ & $\begin{array}{l}175(94.09) 11 \\
(5.91)\end{array}$ & $45(83.33) 9(16.67)$ & 0.012 \\
\hline Symptoms: & 354 & 265 & 89 & \\
\hline Chills & $23(6.5)$ & $16(6.04)$ & $7(7.87)$ & 0.545 \\
\hline Sore throat & $15(4.24)$ & $9(3.4)$ & $6(6.74)$ & 0.175 \\
\hline Weakness & $144(40.68)$ & $103(38.87)$ & $41(46.07)$ & 0.232 \\
\hline Anorexia & $39(11.02)$ & $34(12.83)$ & $5(5.62)$ & 0.060 \\
\hline Anosmia & $1(0.28)$ & $1(0.38)$ & 0 & 0.562 \\
\hline Chest pain & $26(7.34)$ & $20(7.55)$ & $6(6.74)$ & 0.801 \\
\hline Low consciousness & $31(8.76)$ & $7(2.64)$ & $24(26.97)$ & 0.000 \\
\hline Past medical & Past medical & Past medical & Past medical & Past medical \\
\hline history $(\mathrm{PMH})$ & history $(\mathrm{PMH})$ & history $(\mathrm{PMH})$ & history $(\mathrm{PMH})$ & history (PMH) \\
\hline No PMH & $75(21.19)$ & $60(22.64)$ & $15(16.85)$ & 0.248 \\
\hline $\mathrm{DM}$ & $108(30.52)$ & $81(30.57)$ & $27(30.34)$ & 0.968 \\
\hline HTN & $127(35.88)$ & $96(36.23)$ & $31(34.83)$ & 0.812 \\
\hline IHD & $89(25.14)$ & $62(23.4)$ & $27(20.24)$ & 0.192 \\
\hline CKD & $14(2.26)$ & $11(2.26)$ & $3(2.25)$ & 0.773 \\
\hline Cancer & $40(11.3)$ & $22(8.3)$ & $18(20.22)$ & 0.002 \\
\hline Kidney & $9(2.54)$ & $2(0.75)$ & $7(7.87)$ & 0.000 \\
\hline \multicolumn{5}{|l|}{ Transplant } \\
\hline \multicolumn{5}{|l|}{ Signs: } \\
\hline \multicolumn{5}{|l|}{$\mathrm{O}_{2}$ Saturation } \\
\hline$>95 \% 90-95 \%$ & $129(37.61) 153$ & $73(28.52) 130$ & $56(64.37) 23$ & 0.000 \\
\hline$<90 \%$ & $(44.61) 61(17.78)$ & $(50.78) 53(20.70)$ & $(26.44) 8(9.20)$ & \\
\hline \multicolumn{5}{|c|}{ 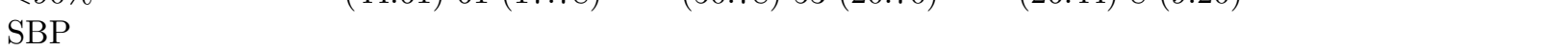 } \\
\hline$<100100-140>140$ & $\begin{array}{l}26(7.54) 228 \\
(66.09) 91(26.38)\end{array}$ & $\begin{array}{l}13(5.06) 166 \\
(64.59) 78(30.35)\end{array}$ & $\begin{array}{l}13(14.77) 62 \\
(70.45) 13(14.77)\end{array}$ & 0.001 \\
\hline \multicolumn{5}{|l|}{ DBP } \\
\hline \multirow[t]{2}{*}{$<7070-90>90$} & $75(21.74) 202(58.55)$ & $49(19.07) 150(58.37)$ & $26(29.55) 52(59.09)$ & 0.024 \\
\hline & $68(19.71)$ & $58(22.57)$ & $10(11.36)$ & \\
\hline \multicolumn{5}{|l|}{$\mathrm{RR}$} \\
\hline$<25>25$ & $\begin{array}{l}298(87.91) 41 \\
(12.09)\end{array}$ & $\begin{array}{l}237(92.22) 20 \\
(7.78)\end{array}$ & $\begin{array}{l}61(74.39) 21 \\
(25.61)\end{array}$ & 0.0000 \\
\hline \multicolumn{5}{|l|}{$\mathrm{PR}$} \\
\hline$<100>100$ & $\begin{array}{l}214(63.31) 124 \\
(36.69)\end{array}$ & $\begin{array}{l}175(68.36) 81 \\
(31.64)\end{array}$ & $\begin{array}{l}39(47.56) 43 \\
(52.44)\end{array}$ & 0.0715 \\
\hline \multicolumn{5}{|l|}{ Temperature } \\
\hline$<37.837 .8-39>39$ & 236(68.41) 92(26.67) & $182(70.82) 66(25.68)$ & $54(61.36) 26(29.55)$ & 0.068 \\
\hline & $17(4.93)$ & $9(3.5)$ & $8(9.09)$ & \\
\hline
\end{tabular}


\# Percentages were calculated by total, survived, and non-survived patients number as denominator for each column respectively.

\begin{tabular}{|c|c|c|c|c|}
\hline & Total & Survived & Non-survived & $p$ value \\
\hline $\begin{array}{l}\text { Intubation } \mathrm{n} \\
(\% \#)(\text { total } \\
\mathrm{n}=354)\end{array}$ & $95(26.84)$ & $10(3.77)$ & $85(95.51)$ & 0.000 \\
\hline $\begin{array}{l}\text { Noninvasive } \\
\text { ventilation; } \mathrm{n}(\%)\end{array}$ & $28(7.91)$ & $13(4.91)$ & $15(16.85)$ & 0.000 \\
\hline $\begin{array}{l}\text { Without any } \\
\text { support; n (\%) }\end{array}$ & $64(18.08)$ & $63(23.77)$ & $1(1.12)$ & 0.000 \\
\hline $\begin{array}{l}\text { ICU admission; } \mathrm{n} \\
(\%)\end{array}$ & $117(33.05)$ & $32(12.08)$ & $85(95.51)$ & 0.000 \\
\hline $\begin{array}{l}\text { Hospital stay, (total } \\
\mathrm{n}=345 \text { ); days Mean } \\
(\mathrm{SD})\end{array}$ & $5.98(5.87)$ & $5.07(4.58)$ & $8.60(8.03)$ & 0.0003 \\
\hline
\end{tabular}

\# Percentages were calculated by total, survived, and non-survived patients number as denominator for each column respectively.

Table 2. Laboratory findings and imaging results categorized in survived and non-survived subgroups.

\begin{tabular}{|c|c|c|c|c|}
\hline & Total n $(\% \#)$ & Survived n (\%) & Non-survived n (\%) & $\mathrm{P}$ value \\
\hline \multicolumn{5}{|l|}{$\mathrm{Hb}$} \\
\hline$<10>10$ & $\begin{array}{l}51(15.18) 285 \\
(84.82)\end{array}$ & $\begin{array}{l}29(11.65) 220 \\
(88.35)\end{array}$ & $\begin{array}{l}22(25.29) 65 \\
(74.71)\end{array}$ & 0.0001 \\
\hline \multicolumn{5}{|l|}{ WBC } \\
\hline $\begin{array}{l}<40004000-12000 \\
>12000\end{array}$ & $\begin{array}{l}63(18.75) 211 \\
(62.80) 62(18.45)\end{array}$ & $\begin{array}{l}45(18.07) 167 \\
(67.07) 37(14.86)\end{array}$ & $\begin{array}{l}18(20.69) 44 \\
(50.57) 25(28.74)\end{array}$ & 0.0182 \\
\hline \multicolumn{5}{|l|}{ Lymphocyte } \\
\hline $\begin{array}{l}<10001000-4000 \\
>4000\end{array}$ & $\begin{array}{l}108(44.26) 127 \\
(52.05) 9(3.69)\end{array}$ & $\begin{array}{l}73(40.11) 103 \\
(56.59) 6(3.3)\end{array}$ & $\begin{array}{l}35(56.45) 24 \\
(38.71) 3(4.84)\end{array}$ & 0.8253 \\
\hline \multicolumn{5}{|l|}{ Neutrophil } \\
\hline $\begin{array}{l}<15001500-7700 \\
>7700\end{array}$ & $\begin{array}{l}11(4.51) 168 \\
(68.85) 65(26.64)\end{array}$ & $\begin{array}{l}10(5.49) 131 \\
(71.98) 41(22.53)\end{array}$ & $\begin{array}{l}1(1.61) 37(59.68) \\
24(38.71)\end{array}$ & 0.0222 \\
\hline \multicolumn{5}{|l|}{ Platelet } \\
\hline$<150000>150000$ & $\begin{array}{l}104(31.23) 229 \\
(68.77)\end{array}$ & $\begin{array}{l}66(26.83) 180 \\
(73.17)\end{array}$ & $\begin{array}{l}38(43.68) 49 \\
(56.32)\end{array}$ & 0.0018 \\
\hline \multicolumn{5}{|l|}{$\mathrm{AST}$} \\
\hline$<40>40$ & $\begin{array}{l}134(49.63) 136 \\
(50.37)\end{array}$ & $\begin{array}{l}110(54.19) 93 \\
(45.81)\end{array}$ & $\begin{array}{l}24(35.82) 43 \\
(64.18)\end{array}$ & 0.0028 \\
\hline \multicolumn{5}{|l|}{$\mathrm{ALT}$} \\
\hline$<40>40$ & $\begin{array}{l}198(72.79) 74 \\
(27.21)\end{array}$ & $\begin{array}{l}156(76.47) 48 \\
(23.53)\end{array}$ & $\begin{array}{l}42(61.76) 26 \\
(38.24)\end{array}$ & 0.2506 \\
\hline \multicolumn{5}{|l|}{ ALK-p } \\
\hline$<200>200$ & $\begin{array}{l}153(57.95) 111 \\
(42.05)\end{array}$ & $\begin{array}{l}120(60.91) 77 \\
(39.09)\end{array}$ & $\begin{array}{l}33(49.25) 34 \\
(50.75)\end{array}$ & 0.1661 \\
\hline \multicolumn{5}{|l|}{ PTT } \\
\hline $\begin{array}{l}<45>45 \\
\text { INR }\end{array}$ & $245(96.46) 9(3.54)$ & $180(96.26) 7(3.74)$ & $65(97.01) 2(2.99)$ & 0.77 \\
\hline
\end{tabular}




\begin{tabular}{|c|c|c|c|c|}
\hline & Total n $(\% \#)$ & Survived n (\%) & Non-survived n (\%) & $\mathrm{P}$ value \\
\hline$<1.5>1.5$ & $209(79.47) 54(20.53)$ & $158(82.29) 34(17.71)$ & $51(71.83) 20(28.17)$ & 0.062 \\
\hline \multicolumn{5}{|l|}{ Total Bilirubin } \\
\hline$<1.5>1.5$ & $\begin{array}{l}166(84.26) 31 \\
(15.74)\end{array}$ & $\begin{array}{l}121(85.82) 20 \\
(14.18)\end{array}$ & $\begin{array}{l}45(80.36) 11 \\
(19.64)\end{array}$ & 0.23 \\
\hline \multicolumn{5}{|l|}{ Creatinine } \\
\hline$<1.2>1.2$ & $\begin{array}{l}205(61.56) 128 \\
(38.44)\end{array}$ & $\begin{array}{l}170(68.83) 77 \\
(31.17)\end{array}$ & $35(40.70) 51(59.3)$ & 0.0016 \\
\hline \multicolumn{5}{|l|}{$\mathrm{Na}$} \\
\hline$<135135-145>145$ & $\begin{array}{l}45(13.68) 269(81.76) \\
15(4.56)\end{array}$ & $\begin{array}{l}29(11.93) 205(84.36) \\
9(3.7)\end{array}$ & $\begin{array}{l}16(18.6) 64(74.42) \\
6(6.98)\end{array}$ & 0.115 \\
\hline \multicolumn{5}{|l|}{$\mathrm{K}$} \\
\hline$<3.53 .5-5>5$ & $\begin{array}{l}9(2.74) 254(77.44) \\
65(19.82)\end{array}$ & $\begin{array}{l}5(2.05) 201(82.38) \\
38(15.57)\end{array}$ & $\begin{array}{l}4(4.76) 53(63.1) \\
27(32.14)\end{array}$ & 0.001 \\
\hline \multicolumn{5}{|l|}{$\mathrm{pH}$} \\
\hline$<7.257 .25-7.35$ & $17(5.12) 48$ (14.46) & $8(3.25) 32(13.01)$ & $9(10.47) 16(18.6)$ & 0.0005 \\
\hline $7.35-7.45>7.45$ & $\begin{array}{l}224(67.47) 43 \\
(12.95)\end{array}$ & $\begin{array}{l}174(70.73) 32 \\
(13.01)\end{array}$ & $\begin{array}{l}50(58.14) 11 \\
(12.79)\end{array}$ & \\
\hline \multicolumn{5}{|l|}{$\mathrm{PCO}_{2}$} \\
\hline$<3535-45>45$ & $\begin{array}{l}93(29.71) 139 \\
(44.41) 81(25.88)\end{array}$ & $\begin{array}{l}57(24.68) 111 \\
(48.05) 63(27.27)\end{array}$ & $\begin{array}{l}36(43.9) 28(34.15) \\
18(21.95)\end{array}$ & 0.0433 \\
\hline \multicolumn{5}{|l|}{$\mathrm{HCO}_{3}$} \\
\hline$<2222-26>26$ & $\begin{array}{l}95(30.35) 118 \\
(37.70) 100(31.95)\end{array}$ & $\begin{array}{l}55(23.81) 92 \\
(39.83) 84(36.36)\end{array}$ & $\begin{array}{l}40(48.78) 26 \\
(31.71) 16(19.51)\end{array}$ & 0.0000 \\
\hline \multicolumn{5}{|l|}{$\mathrm{UA} \gamma$} \\
\hline Hematuria (n ;\%) & $57(34.34)$ & $37(31.36)$ & $20(41.67)$ & $\begin{array}{lll}0.205 & 0.371 & 0.022\end{array}$ \\
\hline Leukocyturia (n & $31(18.67)$ & $20(16.95)$ & $11(22.92)$ & \\
\hline $\begin{array}{l}; \%) \text { Proteinuria } \\
(\mathrm{n} ; \%)\end{array}$ & $64(38.55)$ & $39(33.05)$ & $25(52.08)$ & \\
\hline CT findings: & n 239 & n 179 & n 60 & \\
\hline GGO & $222(92.89)$ & $168(93.85)$ & $54(90) 53(88.33)$ & $\begin{array}{lll}0.315 & 0.050 & 0.229\end{array}$ \\
\hline Consolidation & $190(79.5)$ & $137(76.54)$ & $58(96.67)$ & \\
\hline $\begin{array}{l}\text { Bilateral } \\
\text { involvement }\end{array}$ & $223(93.31)$ & $165(92.18)$ & & \\
\hline
\end{tabular}

$\curlyvee$ N Total=166, Survived:118, Survived:48

\# Percentages were calculated by total, survived, and non-survived patients number as denominator for each column respectively.

Table 3. Results of the univariate and multivariate analysis model.

\begin{tabular}{lllll}
\hline & Univariate analysis & Univariate analysis & Multivariate analysis & Multivariate analysis \\
\hline Variables & Odds ratio (CI95\%) & P value & Odds ratio (CI95\%) & P value \\
Age & Age & Age & Age & Age \\
$<50$ & Ref. & & Ref. & \\
$50-64$ & $1.53(0.70-3.34)$ & 0.284 & $1.36(0.45-4.08)$ & 0.587 \\
$>64$ & $3.09(1.51-6.33)$ & 0.002 & $1.70(0.58-5.00)$ & 0.335 \\
Sex & Sex & Sex & Sex & Sex \\
female & Ref. & & Ref. & \\
male & $1.53(0.93-2.51)$ & 0.097 & $2.01(0.89-4.53)$ & 0.091
\end{tabular}




\begin{tabular}{|c|c|c|c|c|}
\hline & Univariate analysis & Univariate analysis & Multivariate analysis & Multivariate analysis \\
\hline Consciousness & Consciousness & Consciousness & Consciousness & Consciousness \\
\hline Awareness & Ref. & & Ref. & \\
\hline Non awareness & $13.61(5.62-32.97)$ & 0.000 & $6.98(1.99-24.46)$ & 0.002 \\
\hline Anorexia & Anorexia & Anorexia & Anorexia & Anorexia \\
\hline $\mathrm{NO}$ & Ref. & & Ref. & \\
\hline Yes & $0.40(0.15-1.07)$ & 0.068 & $0.25(0.07-0.96)$ & 0.044 \\
\hline \multicolumn{5}{|l|}{ Cancer } \\
\hline $\mathrm{NO}$ & Ref. & & Ref. & \\
\hline Yes & $2.80(1.42-5.51)$ & 0.003 & $4.20(1.39-12.71)$ & 0.011 \\
\hline \multicolumn{5}{|c|}{ Kidney transplant } \\
\hline $\mathrm{NO}$ & Ref. & & Ref. & \\
\hline Yes & $11.23(2.29-55.10)$ & 0.003 & $8.95(0.71-112.85)$ & 0.090 \\
\hline $\mathrm{O}_{2}$ Saturation & $\mathrm{O}_{2}$ Saturation & $\mathrm{O}_{2}$ Saturation & $\mathrm{O}_{2}$ Saturation & $\mathrm{O}_{2}$ Saturation \\
\hline$>95 \%$ & Ref. & & Ref. & \\
\hline $90-95 \%$ & $1.17(0.49-2.79)$ & 0.719 & $1.01(0.31-3.37)$ & 0.981 \\
\hline$<90 \%$ & $5.08(2.24-11.55)$ & 0.000 & $3.99(1.19-13.43)$ & 0.025 \\
\hline SBP & SBP & SBP & SBP & SBP \\
\hline $100-140$ & Ref. & & Ref. & \\
\hline$<100$ & $2.68(1.18-6.09)$ & 0.019 & $0.75(0.20-2.78)$ & 0.672 \\
\hline$>140$ & $0.45(0.23-0.86)$ & 0.016 & $0.49(0.20-1.20)$ & 0.119 \\
\hline Temperature & Temperature & Temperature & Temperature & Temperature \\
\hline$<37.8$ & Ref. & & Ref. & \\
\hline $37.8-39$ & $1.33(0.77-2.29)$ & 0.309 & $1.50(0.66-3.42)$ & 0.330 \\
\hline$>39$ & $3.00(1.10-8.14)$ & 0.031 & $1.11(0.18-6.81)$ & 0.914 \\
\hline $\mathrm{RR}$ & $\mathrm{RR}$ & $\mathrm{RR}$ & $\mathrm{RR}$ & $\mathrm{RR}$ \\
\hline$<25$ & Ref. & & Ref. & \\
\hline$>25$ & $4.08(2.08-8.00)$ & 0.000 & $2.09(0.72-6.03)$ & 0.175 \\
\hline PR & $\mathrm{PR}$ & PR & $\mathrm{PR}$ & $\mathrm{PR}$ \\
\hline$<100$ & Ref. & & Ref. & \\
\hline$>100$ & $2.38(1.43-3.96)$ & 0.001 & $2.60(1.21-5.56)$ & 0.014 \\
\hline $\mathrm{Hb}$ & $\mathrm{Hb}$ & $\mathrm{Hb}$ & $\mathrm{Hb}$ & $\mathrm{Hb}$ \\
\hline$>10$ & Ref. & & Ref. & \\
\hline$<10$ & $2.57(1.38-4.77)$ & 0.003 & $1.84(0.64-5.24)$ & 0.256 \\
\hline WBC & WBC & WBC & WBC & WBC \\
\hline $4000-12000$ & Ref. & & Ref. & \\
\hline$<4000$ & $1.49(0.78-2.85)$ & 0.234 & $0.71(0.24-2.13)$ & 0.544 \\
\hline$>12000$ & $2.54(1.39-4.65)$ & 0.003 & $1.78(0.72-4.40)$ & 0.211 \\
\hline Platelet & Platelet & Platelet & Platelet & Platelet \\
\hline$>150000$ & Ref. & & Ref. & \\
\hline$<150000$ & $2.12(1.27-3.52)$ & 0.004 & $3.11(1.39-6.99)$ & 0.006 \\
\hline \multicolumn{5}{|l|}{ Creatinine } \\
\hline$<1.2$ & Ref. & & Ref. & \\
\hline$>1.2$ & $3.35(2.01-5.57)$ & 0.000 & $3.36(1.45-7.78)$ & 0.005 \\
\hline $\mathrm{pH}$ & $\mathrm{pH}$ & $\mathrm{pH}$ & $\mathrm{pH}$ & $\mathrm{pH}$ \\
\hline $7.35-7.45$ & Ref. & & Ref. & \\
\hline$<7.25$ & $3.92(1.44-10.67)$ & 0.008 & $3.58(0.74-17.32)$ & 0.112 \\
\hline $7.25-7.34$ & $1.74(0.88-3.43)$ & 0.109 & $1.78(0.62-5.12)$ & 0.280 \\
\hline$>7.45$ & $1.20(0.56-2.54)$ & 0.641 & $2.37(0.79-7.12)$ & 0.123 \\
\hline CRP & $\mathrm{CRP}$ & $\mathrm{CRP}$ & $\mathrm{CRP}$ & CRP \\
\hline$<67$ & ref. & & & \\
\hline
\end{tabular}




\begin{tabular}{lllll}
\hline & Univariate analysis & Univariate analysis & Multivariate analysis & Multivariate analysis \\
\hline $\mathbf{P} 67$ & $3.29(1.90-5.69)$ & 0.000 & $2.06(0.96-4.39)$ & 0.063 \\
\hline
\end{tabular}

Appendix 1. The additional univariate analysis did not meet the criteria to enter to multivariate analysis.

\begin{tabular}{|c|c|c|}
\hline & Univariate analysis & Univariate analysis \\
\hline Variables & Odds ratio (CI95\%) & $\mathrm{P}$ value \\
\hline BMI & BMI & BMI \\
\hline$<35$ & Ref. & \\
\hline$>35$ & $3.18(1.24-8.14)$ & 0.016 \\
\hline CKD & CKD & CKD \\
\hline No & Ref. & \\
\hline Yes & $0.80(0.21-2.95)$ & 0.744 \\
\hline DBP & $\mathrm{DBP}$ & $\mathrm{DBP}$ \\
\hline $70-90$ & Ref. & \\
\hline$<70$ & $1.53(0.87-2.71)$ & 0.144 \\
\hline$>90$ & $0.50(0.24-1.04)$ & 0.065 \\
\hline Lymphocyte & Lymphocyte & Lymphocyte \\
\hline $1000-4000$ & Ref. & \\
\hline$<1000$ & $2.06(1.13-3.75)$ & 0.018 \\
\hline$>4000$ & $2.15(0.50-9.20)$ & 0.304 \\
\hline Neutrophil & Neutrophil & Neutrophil \\
\hline $1500-7700$ & Ref. & \\
\hline$<1500$ & $0.35(0.04-2.86)$ & 0.330 \\
\hline$>7700$ & $2.07(1.11-3.86)$ & 0.022 \\
\hline NLR(neutrophil- lymphocyte ratio) & $1.11(1.05-1.16)$ & 0.000 \\
\hline $\mathrm{AST}$ & $\mathrm{AST}$ & $\mathrm{AST}$ \\
\hline$<40$ & Ref. & \\
\hline$>40$ & $2.12(1.20-3.75)$ & 0.010 \\
\hline ALT & ALT & ALT \\
\hline$<40$ & Ref. & \\
\hline$>40$ & $2.01(1.12-3.62)$ & 0.019 \\
\hline ALK-p & ALK-p & ALK-p \\
\hline$<200$ & Ref. & \\
\hline$>200$ & $1.61(0.92-2.81)$ & 0.096 \\
\hline Total bilirubin & Total bilirubin & Total bilirubin \\
\hline$<1.5$ & Ref. & \\
\hline$>1.5$ & $1.48(0.66-3.33)$ & 0.345 \\
\hline \multicolumn{3}{|l|}{ PTT } \\
\hline$<45$ & Ref. & \\
\hline$>45$ & $0.79(0.16-3.91)$ & 0.774 \\
\hline \multicolumn{3}{|l|}{ INR } \\
\hline$<1.5$ & Ref. & \\
\hline$>1.5$ & $1.82(0.96-3.44)$ & 0.064 \\
\hline \multicolumn{3}{|l|}{ UA } \\
\hline \multicolumn{3}{|l|}{$\mathrm{RBC}$} \\
\hline$<2$ & Ref. & \\
\hline$>2$ & 1.56 & 0.206 \\
\hline \multicolumn{3}{|l|}{ WBC } \\
\hline$<5$ & Ref. & \\
\hline
\end{tabular}




\begin{tabular}{lll}
\hline & Univariate analysis & Univariate analysis \\
\hline$>5$ & $1.46(0.64-3.33)$ & 0.373 \\
$\mathrm{Pr}$ & Ref. & \\
Negative & $2.20(1.11-4.36)$ & 0.24 \\
Positive & $\mathrm{PCO}_{2}$ & $\mathrm{PCO}_{2}$ \\
$\mathrm{PCO}_{2}$ & Ref. & \\
$35-45$ & $2.5(1.39-4.51)$ & 0.002 \\
$<35$ & $1.13(0.58-2.21)$ & 0.715 \\
$>45$ & $\mathrm{HCO}_{3}$ & $\mathrm{HCO}_{3}$ \\
$\mathrm{HCO}_{3}$ & Ref. & \\
$22-26$ & $2.57(1.42-4.67)$ & 0.002 \\
$<22$ & $0.67(0.34-1.34)$ & 0.262 \\
$>26$ & Bilateral CT involvement & Bilateral CT involvement \\
Bilateral CT involvement & Ref. & \\
No & $2.46(0.54-11.16)$ & 0.243 \\
Yes & GGO pattern in CT scan & GGO pattern in CT scan \\
GGO pattern in CT scan & Ref. & \\
No & $0.59(0.21-1.67)$ & 0.319 \\
Yes & Consolidation pattern in CT scan & Consolidation pattern in CT scan \\
Consolidation pattern in CT scan & Ref. & \\
NO & $2.32(0.98-5.49)$ & 0.055 \\
Yes & & \\
\hline
\end{tabular}

